\title{
Convective Heat Transfer Scaling of Ignition Delay and Burning Rate with Heat Flux and Stretch Rate in the Equivalent Low Stretch Apparatus
}

\author{
SANDRA L. OLSON \\ NASA Glenn Research Center at Lewis Field \\ 21000 Brookpark Rd., Mail Stop 77-5 \\ Cleveland, OH 44135 USA
}

\begin{abstract}
To better evaluate the buoyant contributions to the convective cooling (or heating) inherent in normal gravity material flammability test methods, we derive a convective heat transfer correlation that can be used to account for the forced convective stretch effects on the net radiant heat flux for both ignition delay time and burning rate. The equivalent low stretch apparatus (ELSA) uses an inverted cone heater to minimize buoyant effects while at the same time providing a forced stagnation flow on the sample, which ignites and burns as a ceiling fire. Ignition delay and burning rate data is correlated with incident heat flux and convective heat transfer and compared to results from other test methods and fuel geometries using similarity to determine the equivalent stretch rates and thus convective cooling (or heating) rates for those geometries. With this correlation methodology, buoyant effects inherent in normal gravity material flammability test methods can be estimated, to better apply the test results to low stretch environments relevant to spacecraft material selection.
\end{abstract}

KEYWORDS: cone heater, ignition, burning rate, convective heat transfer, low stretch.

\section{NOMENCLATURE LISTING}

a stretch rate $(1 / \mathrm{s})$

$c \quad$ heat capacity $(\mathrm{kJ} / \mathrm{kg} \mathrm{K})$

$d \quad$ diameter of jet (m)

$\mathrm{Fr} \quad$ Froude number

$g \quad$ gravity level relative to $1-\mathrm{g}$

$k$ thermal conductivity $(\mathrm{kW} / \mathrm{m} \mathrm{K})$

$q^{\prime \prime} \quad$ heat flux $\left(\mathrm{kW} / \mathrm{m}^{2}\right)$

$R \quad$ radius of curvature (m)

$\mathrm{Nu} \quad$ Nussult number

$t \quad$ time (s)

$T$ temperature (K)

$U \quad$ velocity $(\mathrm{m} / \mathrm{s})$

$W \quad$ velocity component normal to surface $(\mathrm{m} / \mathrm{s})$

$Z \quad$ distance normal to surface (m)

Greek

$\eta \quad$ non-dimensional distance from surface

$\rho \quad$ density $\left(\mathrm{kg} / \mathrm{m}^{3}\right)$

\begin{tabular}{ll}
\multicolumn{2}{l}{ subscripts } \\
$b$ & buoyant \\
$c$ & convective \\
Earth & value on Earth \\
equiv & equivalent \\
ext & external \\
$f$ & forced \\
flame & flame \\
jet & jet \\
ign & ignition \\
net & net \\
rad & radiation \\
sphere & sphere \\
$\infty$ & infinity, ambient
\end{tabular}




\section{INTRODUCTION}

The equivalent low stretch apparatus (ELSA), shown in Fig. 1, uses an inverted cone geometry with the sample ignition and burning in a ceiling fire (stagnation flow) configuration. In this configuration, the influence of buoyancy is reduced because the rise of hot gases is inhibited. The buoyant stagnation flow around the sample acts in the same direction as a variable forced convective stagnation flow, so that the mixed convective stretch rate (velocity gradient) near the fuel surface can be varied [1-3].

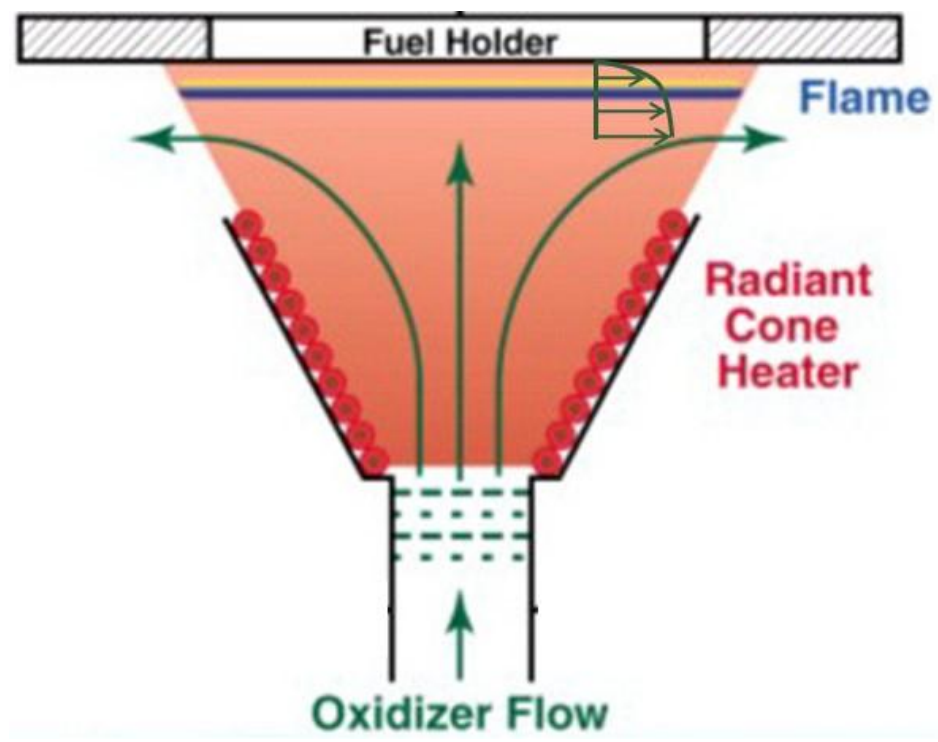

Fig. 1. A schematic of the equivalent low stretch apparatus (ELSA), showing the stagnation boundary layer that develops on the sample.

Equivalent stretch rates can be determined as a function of gravity, imposed flow, and geometry. A generalized expression for stretch rate which captures mixed convection includes both buoyant and forced stretch is defined [1] as $a_{\text {equiv }}=a_{f}\left(1+a_{b}^{2} / a_{f}^{2}\right)^{1 / 2}$. The forced flow stretch rate is characterized by $a_{f}=U_{j e t} / d_{j e t}$ for a jet impinging on a planar surface [4], where $U_{j e t}$ is the velocity the jet and $d_{j e t}$ is the diameter of the jet. The buoyant stagnation flow is $\sim 4 \mathrm{~s}^{-1}[4]$, and scales with gravity as $a_{b} \sim[g / R]^{1 / 2}[1,2]$, where $\mathrm{g}$ is gravity and $R$ is the radius of curvature of the sample.

The $10 \mathrm{~cm}$ square sample is ignited and burned above the radiant heater. In this configuration, the velocity gradient normal to the flame sheet is dominated by the velocity of the incoming flow rather than buoyancy except at very low jet velocities. Tests have been performed on various materials such as Combitherm ${ }^{\mathrm{TM}}$, Kevlar $^{\mathrm{TM}}$, Nomex ${ }^{\mathrm{TM}}$, Pyrell ${ }^{\mathrm{TM}}$ foam, and $\mathrm{Kydex}^{\mathrm{TM}}$ to evaluate the suitability of this test for a range of materials. Modeling of the flow field, and flow visualization in the hardware have demonstrated very low stretch rates $\left(\sim 4 \mathrm{~s}^{-1}\right)$ [5]. Figure 2 shows an isothermal flow visualization image at $5 \mathrm{~s}^{-1}$ as well as an FDS model [6] $W$-velocity gradient for a $30 \mathrm{~cm} / \mathrm{s}$ jet and a $7.5 \mathrm{~cm}$ diameter nozzle with the cone at $950 \mathrm{~K}$ and the sample at $600 \mathrm{~K}$. The inset to Fig. $2 \mathrm{~b}$ shows the centerline gradient evaluated from $3 \mathrm{~cm}<Z<9 \mathrm{~cm}$ compared to $U / d$ stretch scaling. The computed gradient agrees with stretch rate predicted by theory. 

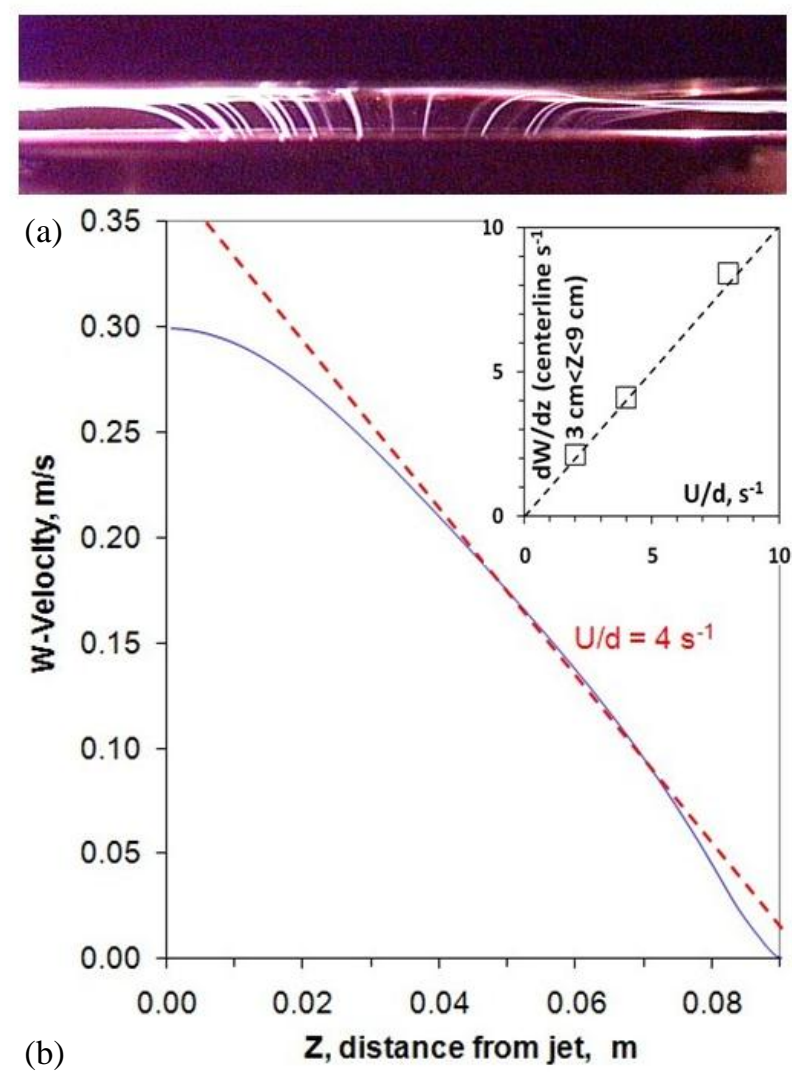

Fig. 2. (a) Flow visualization in inverted cone geometry showing stagnation flow impinging on the sample; (b) FDS centerline velocity profile computation of cone geometry. Inset shows FDS velocity gradient compared to $U / d$ stretch scaling.

\section{BOUNDARY LAYER SCALING}

Wichman [7] proposed that the flame spreading mechanism is controlled by local conditions of the flow field, as described by the surface velocity gradient. This implies that the flame spread rates measured in two (or more) different experiments may be identical even though the external flow conditions of these experiments differ significantly (for all other factors such as free-stream oxidizer concentration and solid fuel material remaining the same).

Blasius boundary layer theory provides a linear velocity profile near the wall, which is a constant stretch (velocity gradient) environment. Notice in Fig. 3 that in the boundary layer region $0 \leq \eta \leq 1$; $0 \leq U / U_{\infty} \leq 0.63$ the gradient is linear. Flames that reside within this region are subject to a constant stretch rate. For forced flow velocities of $0-20 \mathrm{~cm} / \mathrm{s}$ (near-wall spacecraft ventilation flows), the velocity gradient (stretch rate) is $0-33 \mathrm{~s}^{-1}$ for small fires $(x=5 \mathrm{~cm})$, as shown in the inset to Fig. 3. The stagnation boundary layer, shown schematically in Fig. 1, can thus be related to other flow geometries. 


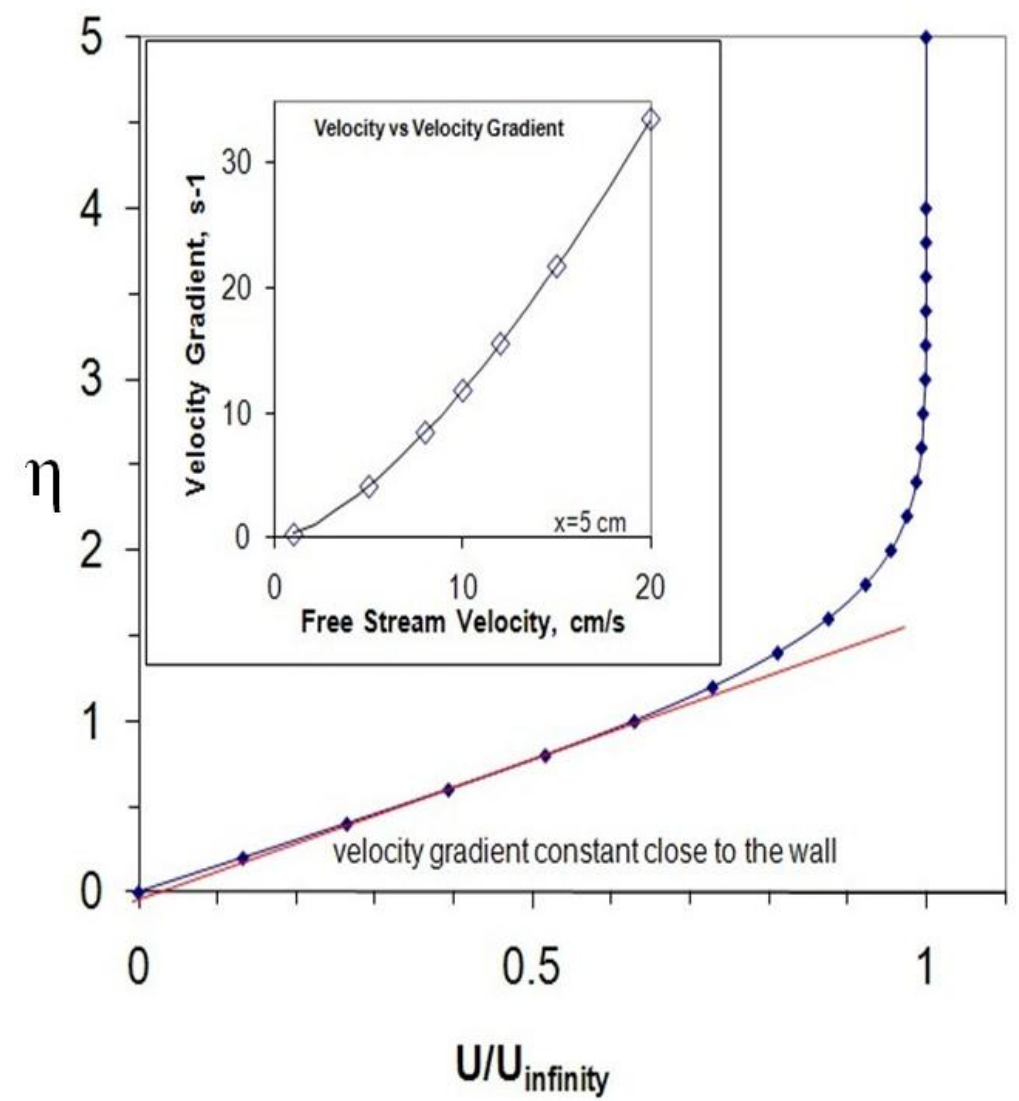

Fig. 3. Linear velocity profile showing constant velocity gradient ('stretch rate') within boundary layer. Velocity gradient as a function of free stream velocity is shown in the inset.

To demonstrate this scaling concept with experimental results, the ignition delay time results of FIST (forced ignition and flame spread test) experiments during low gravity parabolic aircraft testing [8] at different flow rates, including natural convection, are added to the previous ignition delay time data [4] in a new ignition delay-stretch rate or equivalent gravity level plot, shown in Fig. 4, by estimating the Blasius boundary layer velocity gradient at the surface for the free-stream flow based on the FIST experiment geometry (gradient evaluated at $x=22 \mathrm{~cm}$ ). The stretch correlation holds up very well up to $\sim 100 \mathrm{~s}^{-1}$ stretch rates, but breaks down at very high forced flow stretch rates (not shown), possibly due to a transition to turbulent flow affecting the entrance length boundary layer flow within the duct, and thus affecting the convective heat and mass transfer.

Also included is the 1-g standard cone data, with a secondary equivalent gravity level axis shown below the equivalent stretch rate axis based on Froude number scaling $\left(\mathrm{Fr}=U /(g d)^{1 / 2}\right)$. For $a=U / d$, a constant Froude number and geometry provides $a \sim g^{1 / 2}$, in agreement with the above $a_{b} \sim[g / R]^{1 / 2}[1,2]$ Using the buoyancydominated normal cone result that indicates that $1-\mathrm{g} \sim 33 \mathrm{~s}^{-1}[4]$ and this scaling allows the calculation of this second axis in both Fig. 4 and 5. ELSA data is in the partial gravity range. 


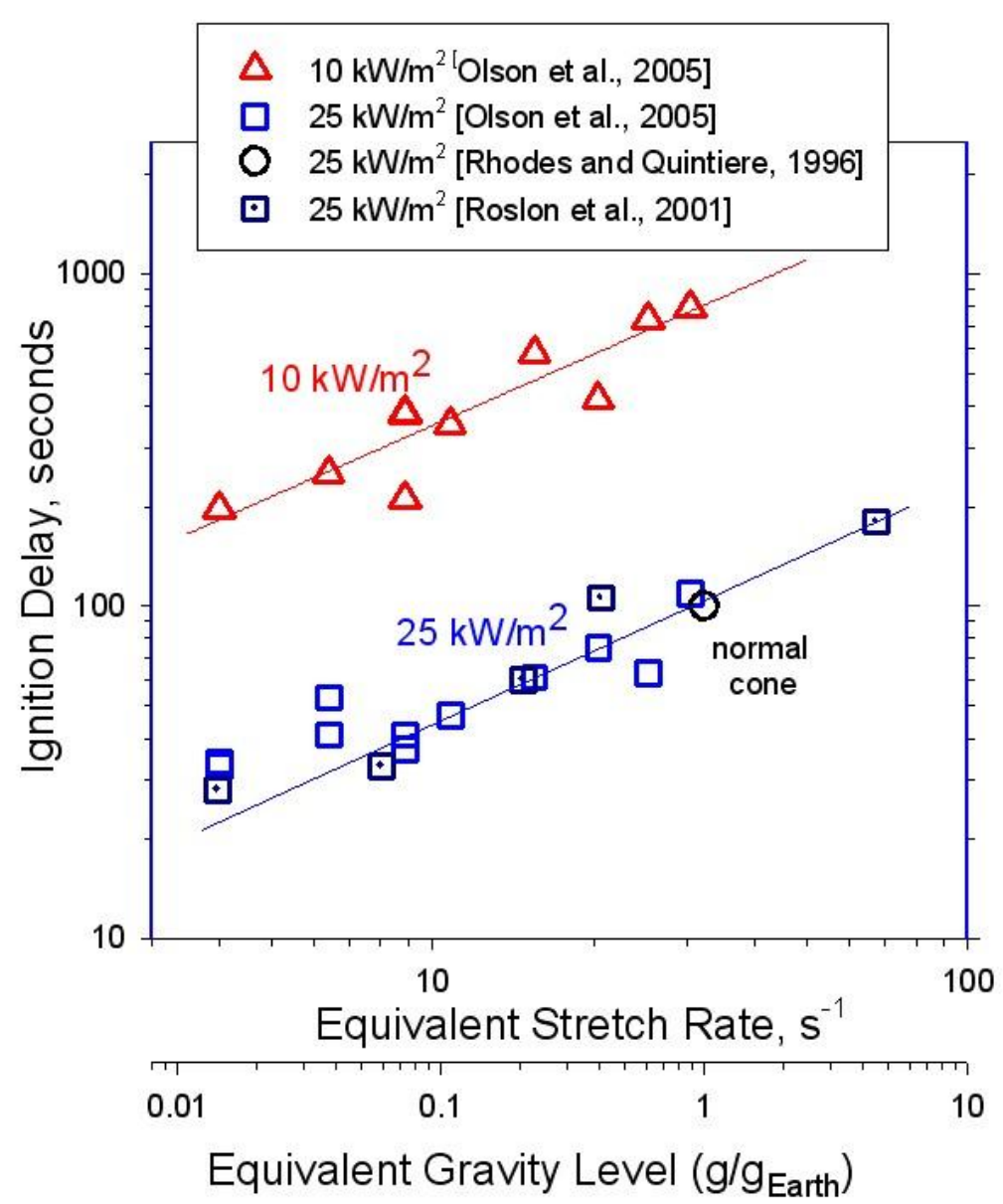

Fig. 4. Using boundary layer velocity gradient scaling, FIST KC-135 (Roslon et al.) [8] and 1-g cone (Rhodes and Quintiere) [9] ignition delay times agree well with previous low stretch data.

\section{REGRESSION RATE}

Stretch is induced not only by velocity gradients, but also by flame curvature. A flammability study of different materials, including PMMA, was conducted aboard Mir in their Skorost facility $[10,11]$. Rods of PMMA were burned in a concurrent airflow parallel to the rod axis. Interestingly, the rods developed large molten balls at their burning tips, and in the low flow environment provided by Skorost, the flames were stabilized at the stagnation point of the ball. They measured rod regression rates, molten ball diameters, and flame diameters as a function of ambient forced flow. Using that information, we can estimate the stretch rates and burning rates for these PMMA balls.

Regression rates of molten spheres were calculated by converting the mass loss rate $(\mathrm{g} / \mathrm{s})$ determined from the reported average rod regression rate into the same mass loss rate from the reported size of the molten sphere. The inviscid forced stretch around the sphere is given by $a_{f, s p h e r e}=3 / 2 U / R_{\text {sphere }}$, and the curvatureinduced stretch is estimated for the small samples from $a_{\text {curv }}=\left[\begin{array}{ll}3 & U / R_{\text {sphere }}\end{array} \times\left[\left(R_{\text {flame }}-R_{\text {sphere }}\right) / R_{\text {sphere }}\right]\right.$. The equivalent stretch in this case is approximated as $a_{\text {equiv }}=a_{f, s p h e r e}+a_{\text {curv }}$. As the flame standoff distance $\left(R_{\text {flame }}-R_{\text {sphere }}\right)$ becomes small relative to the radius of curvature, curvature effects become negligible. However, for the small spheres in these experiments $(<1 \mathrm{~cm})$, the curvature effects were significant and needed to be accounted for. The data is plotted in Fig. 5. 


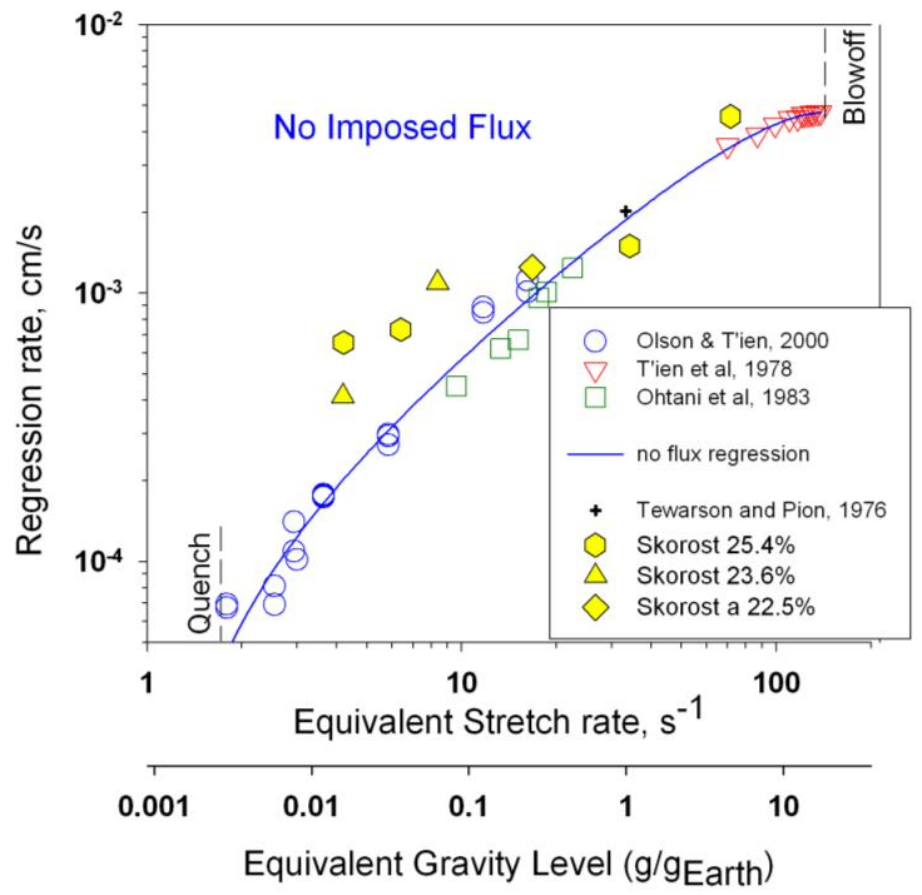

Fig. 5. Graph showing good agreement of stretch flame results [2] with Skorost tests conducted aboard Mir $[10,11]$, and 1-g data [12].

The comparison between Skorost results [10,11] and low stretch average regression rate PMMA results $[2,13,14]$ is very good, especially considering the Skorost tests were conducted in slightly higher oxygen concentrations, which explains why the data is biased above the curve and deviates more at lower stretch where diffusive oxygen transport is more significant. The flame heat release rate will be affected by the ambient oxygen concentration, and an increase in oxygen will result in an increase in the flame heat flux back to the fuel surface, resulting in an increase in burning rate. Lastly, notice on the secondary axis that the data is for conditions corresponding to the partial gravity levels and stretch rates associated with spacecraft ventilation.

\section{IGNITION DELAY}

At low gravity, radiation from a small adjacent burning material may be sufficient to ignite a material. This was observed on Mir [10,11] in their Skorost facility, where the burning molten ball of fuel at the end of a rod of one material heated an adjacent rod to vaporization temperatures (bending, bubbling). The flame from the first rod then acted as the gas-phase pilot for the premixed cloud that developed between the two rods. The premixed flame propagated through the cloud and ignited the heated second rod. The critical heat flux for ignition in the absence of convective cooling is just slightly more than offsets the experimental heat losses such as surface radiation at $T_{i g n}$ [4], which agrees with the model of Rhodes and Quintiere [9] in the limit of no convection, and is consistent with observations that ignition is easier in microgravity [15].

For thermally-thick fuels, the heat-up time is the dominant timescale that controls the ignition delay time. The ignition delay time of a thermally thick fuel exposed to an incident radiative heat flux can be expressed as [16]:

$$
\frac{1}{\sqrt{t_{i g n}}}=\frac{2}{\sqrt{\pi}} \frac{1}{\sqrt{k \rho c}} \frac{\dot{q}_{n e t}^{\prime \prime}}{\left(T_{i g n}-T_{\infty}\right)}
$$

Inverse square root of ignition delay time versus heat flux graphs thus have a linear trend, and the slope of the line is related to the fuel properties $(k \rho c)$ and $\left(T_{i g n}-T_{\infty}\right)$. However, the slope of the line has been found to be apparatus-dependent, and not derivable from fundamental fuel properties [17-19]. 
Ignition delay time is defined as the time between when the sample is exposed to the radiant heater and the time at which sustained ignition is achieved. Ignition delay has been measured as a function of stretch rate for thick PMMA samples at $10 \mathrm{~kW} / \mathrm{m}^{2}$ and $25 \mathrm{~kW} / \mathrm{m}^{2}$ flux levels [4], as shown in Fig. 4. For a fixed radiant flux, ignition delay times are shown to decrease with decreasing equivalent velocity gradient, or g level.

At $25 \mathrm{~kW} / \mathrm{m}^{2}$ the difference between a normal (1-g) cone ignition delay time (high equivalent velocity gradient) and ignition delay times at very low equivalent velocity gradients is a factor of three (see Fig. 4), demonstrating that ignition delay times determined from normal cone tests significantly overestimate the ignition delay times of materials in microgravity or in partial gravity extraterrestrial environments. In addition, at the $10 \mathrm{~kW} / \mathrm{m}^{2}$ flux level, the ignition delay time at low g levels approaches the value of the $1-\mathrm{g}$ normal cone at $25 \mathrm{~kW} / \mathrm{m}^{2}$, indicating the sensitivity of low $\mathrm{g}$ flames to even weak levels of external flux.

The difference between ignition delay times in a normal-gravity cone and ELSA is also shown in Fig. 6 for Kydex 100, a PMMA-PVC blend material commonly used for aircraft interior cabin walls. Kydex 100 sheets $\left(0.15 \mathrm{~cm}\right.$ thick) were ignited in ELSA under no forced stretch rate $\left(a_{b} \sim 4 \mathrm{~s}^{-1}\right)$. Ignition delay time is consistently shorter in ELSA, indicating faster ignition times with reduced convective cooling. The slopes of the curve fits fall between thermally-thick (slope $\sim-2$ ) and thermally-thin (slope $\sim-1$ ), indicating this fuel is of intermediate thickness.

It is interesting to note that Kydex 100 passes NASA STD-6001 Test 1 (upward flammability test) at both $14.7 \mathrm{psia}(101.4 \mathrm{kPa}), 20.9 \% \mathrm{O}_{2}$ and at $14.3 \mathrm{psia}(98.6 \mathrm{kPa}), 25.9 \% \mathrm{O}_{2}$ [20]. However, it only requires a modest $15 \mathrm{~kW} / \mathrm{m}^{2}$ of external heat flux to ignite the material in air in NASA STD-6001 Test 2 (cone calorimeter test) [20].

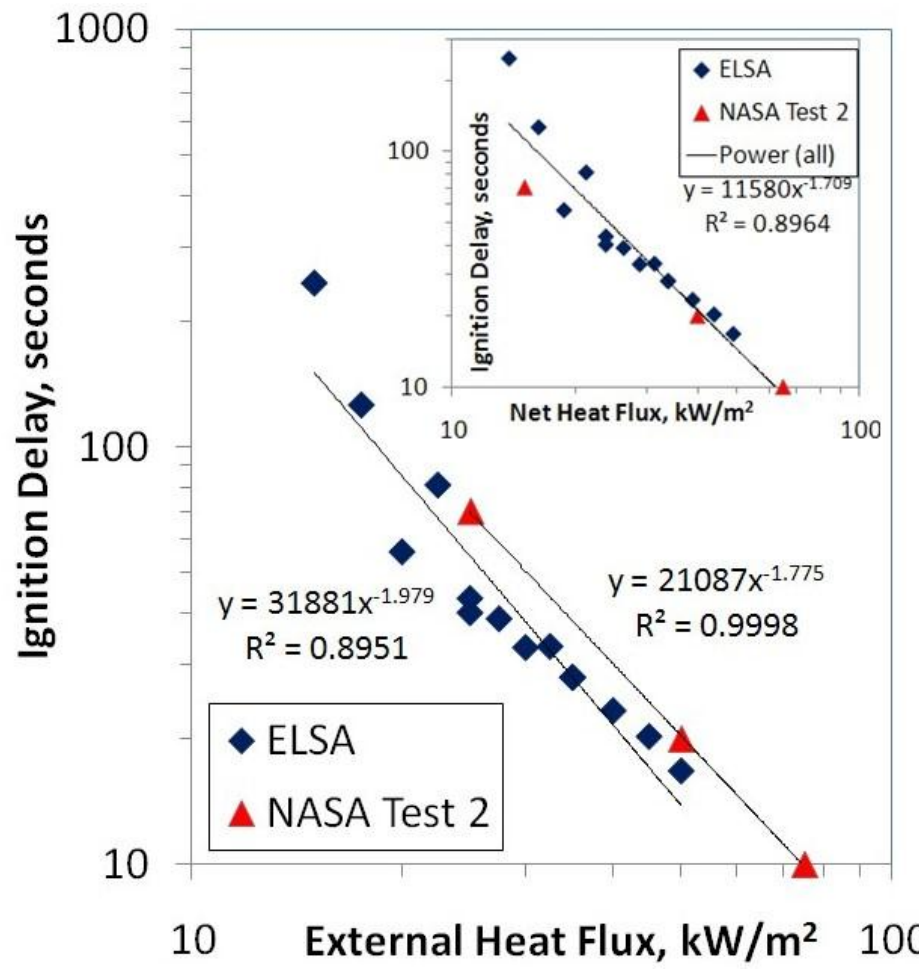

Fig. 6. New ignition delay time data for Kydex 100 versus external heat flux for ELSA is compared to ignition delay obtained in a standard cone calorimeter in 1-g [20]. Inset shows when cooling is accounted for using the convective cooling correlation discussed below, ignition delay data agrees much better.

\section{CONVECTIVE HEAT TRANSFER CORRELATIONS}

One of the major difficulties in evaluating a material's flammability is that different tests rank materials differently. Standard material flammability test methods each provide a unique flow environment with its associated convective heat transfer, and thus direct comparisons between test methods is difficult [17]. 
Most fires are diffusion flames which reside within a fluid mechanical boundary layer, with a bulk flow either due to forced convection or driven by buoyancy. The flow can be parallel to the fuel, or orthogonal to it, or a combination of the two. For example, the LIFT (lateral ignition flame spread test) apparatus provides a natural convective boundary layer on the vertical sample, whereas the FPA (fire propagation apparatus) provides an upward coaxial forced flow past the horizontal sample. The cone calorimeter has natural convection across the horizontal (or vertical) sample, and ELSA provides a stagnation flow impinging on the sample.

Unfortunately, ignition delay time data from different radiant ignition test methods have different slopes, resulting in different TRP values [18]. For example, the $k \rho c$ values reported for PMMA using the LIFT methodology over-predict by a factor of more than four the product of the individual property values [19]. The property values derived from Eq. 1 have been found to be dependent on flow conditions.

The primary reason different tests do not provide the same slope is because of the different convective environments of the tests. To better evaluate the buoyant contributions to the convective cooling (or heating) inherent in normal-gravity test methods, we derive a convective heat transfer correlation that can be used to account for the forced convective stretch effects on the net radiant heat flux for both ignition delay time and burning rate.

For a thermally-thick fuel, the heat-up time is much longer than the gas-phase mixing time. Thus, the ignition delay is driven by the net heat flux. As the net heat flux increases (via reduced convective cooling, for example), the inverse square root of the ignition delay time increases (ignition delay time decreases). From Fernandez-Pello [21], the net flux for stagnation flow can be estimated as $q_{\text {net }}^{\prime \prime}=q_{\text {external }}^{\prime \prime}+q_{c}^{\prime \prime}-q_{\text {rad }}^{\prime \prime}$, which corrects for convective and surface radiation.

During heat-up, the convective heat transfer increases as the temperature difference between the ambient air flow and the heating surface increases. The convective heat cooling rate is thus a maximum at ignition. After ignition, the presence of the flame and the buoyant flow result in a convective heating effect. The fluid dynamics and heat transfer associated with impinging jets is very complex, and still not completely understood, and there is no generally established functional relationship with Nussult number [22]. The convective heat transfer coefficient can be related to stretch rate through similarity between thermal and viscous boundary layers. It is reasonable to approximate that the convective heat transfer coefficient $h_{c}$ is proportional to $a$, the stretch rate. This linear approximation has a better empirical fit to the data than the classic square root dependence, where data at different stretch rates remain stratified.

Prior to ignition, forced convection of ambient air to the irradiated hot surface has a cooling effect, whereas after ignition, an increase in the stagnation flow presses the flame closer to the fuel surface, increasing the heat flux. We estimate the convective effect to be $q_{c}^{\prime \prime}=(0.001 a) \Delta T \mathrm{~kW} / \mathrm{m}^{2}$, where $\Delta T$ is $\sim-300 \mathrm{~K}$ for ignition and $\sim 1000 \mathrm{~K}$ for burning. For the range of stretch rates of interest (2-200 s ${ }^{-1}$, Fig. $5 \mathrm{x}$-axis), the heat transfer coefficient $h_{c}=(0.001 a)$ varies over a reasonable range of $0.002-0.2 \mathrm{~kW} / \mathrm{m}^{2} \cdot \mathrm{K}$. This convective heat transfer estimate is used in Eq. 1 to correlate the data for both ignition delay and also to correlate the regression rate. For ignition, Eq. 1 without the radiant loss term becomes

$$
\frac{1}{\sqrt{t_{i g n}}}=\frac{2}{\sqrt{\pi}} \frac{1}{\sqrt{k \rho c}}\left[\frac{\alpha q^{\prime \prime}{ }_{e x t}-0.3 a}{\left(T_{i g n}-T_{\infty}\right)}\right]
$$

where the $q_{c}^{\prime \prime}=(0.001 a) \times 300 K=-0.3 a \mathrm{~kW} / \mathrm{m}^{2}$ is the convective heat transfer estimate from above for ignition and $\alpha$ is absorptivity, assumed to be equal to one. Radiant heat loss $q_{r a d}^{\prime \prime}$ is neglected since it is approximately $5 \mathrm{~kW} / \mathrm{m}^{2}$ and will simply shift all of the results uniformly for the assumed constant $T_{i g n}$.

We use this relationship as a guide to correlate the thermally-thick PMMA ignition delay time with net heat flux in Fig. 7. Stretch rates vary from the buoyant limit of $4 \mathrm{~s}^{-1}$ [4] to $33 \mathrm{~s}^{-1}$, and imposed heat flux varies from $10-75 \mathrm{~kW} / \mathrm{m}^{2}$. The data fits well using the correlation, despite the differences in the experiments. Normal gravity high velocity FIST data $(\mathrm{m} / \mathrm{s}$ flow rates, not shown), however, does not - probably due to turbulence. Low heat flux high convective cooling data shows more scatter, which may be due to an 
overestimation of convective cooling or variation in ignition temperature (Eq. 2) for these near limit very slow ignition tests.

The power law fit has a weaker dependence on net flux than predicted by Eq. 2. Rather than an exponent of -2 , the best fit power law exponent is only -1.43 , which is even lower than the Kydex data from Fig. 6. It is likely that the thermal theory assumption of a constant ignition temperature does not hold throughout the ignitable range.

In Fig. 7, a second equivalent gravity axis is again shown, using the same stretch scaling discussed above, along with normal cone ignition delay-heat flux data [23]. To fix the g axis, a net heat flux of $15.1 \mathrm{~kW} / \mathrm{m}^{2}$ at 1 -g was used $\left(25 \mathrm{~kW} / \mathrm{m}^{2}-0.3 \times 33 \mathrm{~s}^{-1}\right.$, [9]). This axis is only a scaling approximation to demonstrate that as gravity decreases, ignition delays become shorter as convective cooling decreases.

For ignition, the color of the PMMA (clear or black) does not seem to influence the resulting ignition delay time significantly, as shown in Fig. 7, whereas it does make a difference for burning rate [9] as will be discussed below. The long wavelengths of the cone heater are effectively absorbed by the clear as well as the black PMMA.
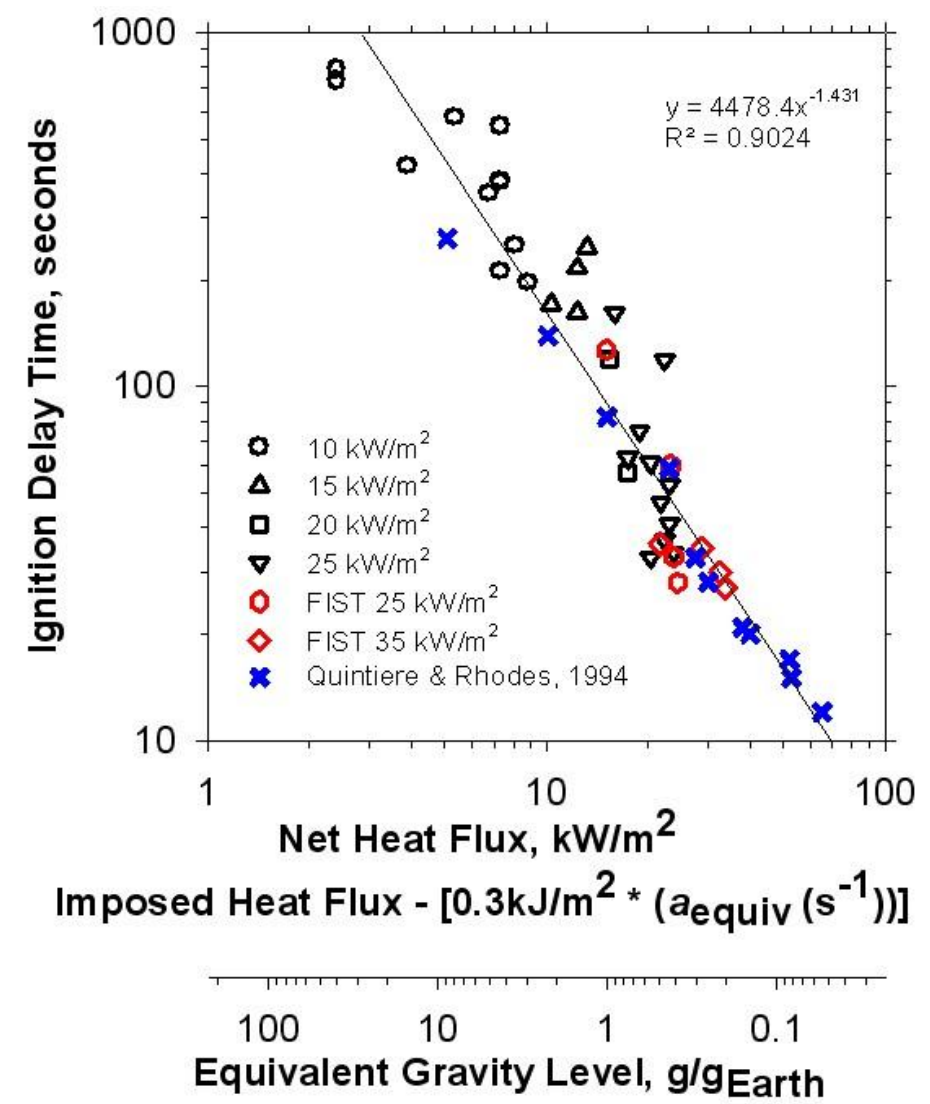

Fig. 7. Ignition delay time for PMMA correlated with net heat flux which includes convective cooling effects. ELSA (clear PMMA) [4], normal cone calorimeter (black PMMA) [23] and low gravity FIST data (clear PMMA) [8] agree well.

Regression data can be evaluated using the same correlation. For steady burning, using the above estimate and $1000 \mathrm{~K}$ for the difference between flame temperature and burning surface temperature, the convective heating effect is $q_{c}^{\prime \prime}=1 a \mathrm{~kW} / \mathrm{m}^{2}$, where the empirical convective coefficient for burning is $1 \mathrm{~kJ} / \mathrm{m}^{2}$. The effect of increasing stretch in the stagnation flow geometry is to push the flame closer to the fuel, in effect increasing the heat flux from the flame to the surface. Using this correlation, the 1-g normal cone equivalent stretch rate of $33 \mathrm{~s}^{-1}$ [4] results in a flame heat flux of $33 \mathrm{~kW} / \mathrm{m}^{2}$, which is in good agreement with the measured flame heat flux of $37 \mathrm{~kW} / \mathrm{m}^{2}$ [23] and estimated heat flux of $38.5 \mathrm{~kW} / \mathrm{m}^{2}$ [12]. 
As shown in Fig. 8, which is a revised version of the no external heat flux data shown in Fig. 5 that now also includes external heat flux data [4], this correlation holds up very well over a $0-25 \mathrm{~kW} / \mathrm{m}^{2}$ range of external flux and stretch rates from $2-150 \mathrm{~s}^{-1}$. The Skorost data $[10,11]$ again trends high especially at low stretch due to the elevated oxygen concentrations on Mir while the rest of the data was taken in ambient air. At higher oxygen, flame heat release rate will be higher, resulting in a higher heat flux than air, so the data would shift to the right if the difference oxygen were accounted for. Estimates of that correction do shift the very low velocity tests correctly, but the higher flow tests (up to $8 \mathrm{~cm} / \mathrm{s}$ ) are shifted too much by the correction, possibly due to a transition to an excess air (fuel lean) condition in the assumed relevant flow volume. The regression rate (or burning rate if regression rate is divided by the fuel density) is linearly proportional to the net heat flux over most of the flammable range, and only falls off this linearity near blowoff and quenching extinction.

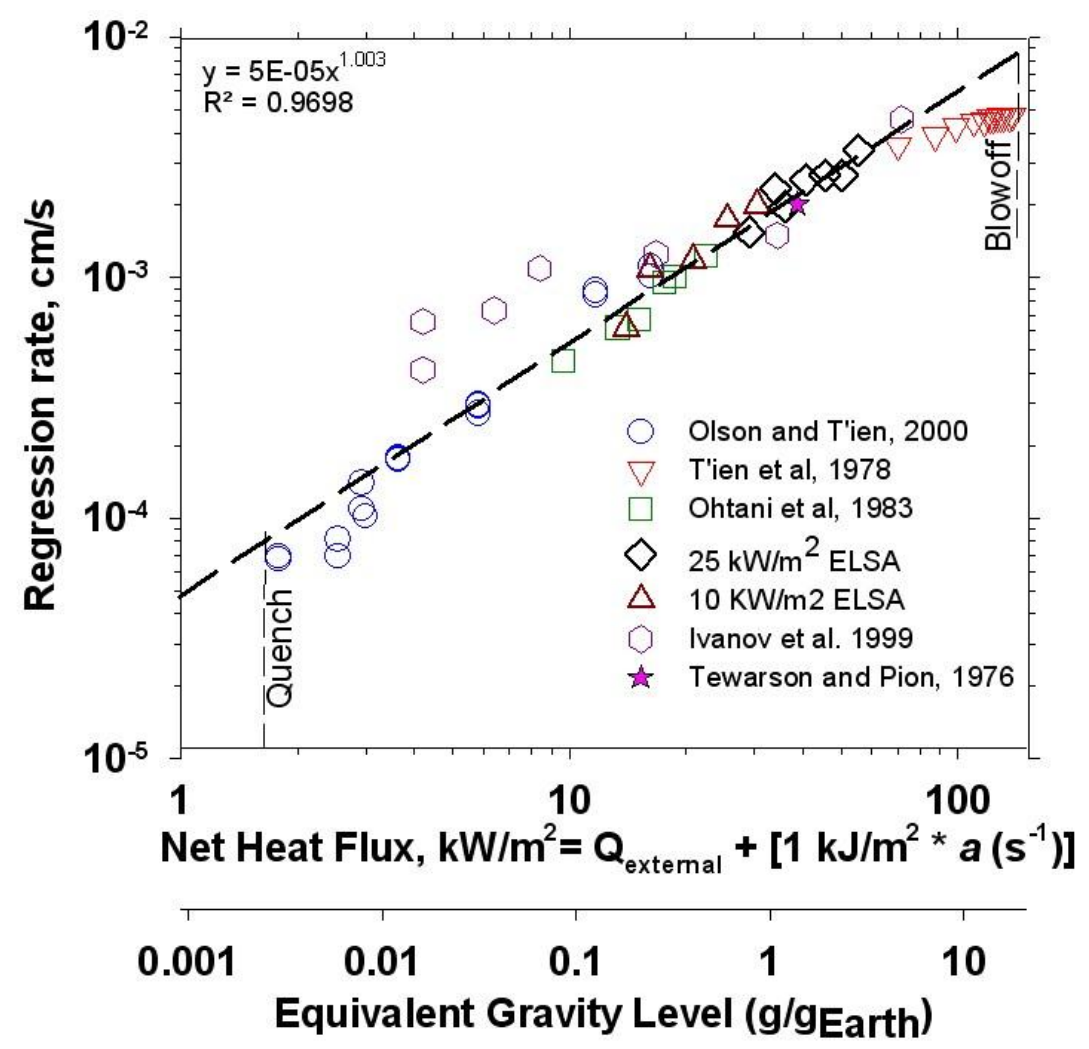

Fig. 8. PMMA regression rate data $[2,4,10-14]$ correlated with net flux. Data from references as noted in legend. Some data with external heat flux and stretch rate, other data no external heat flux. No external heat flux data from Ref. [12] is estimated from their flame to surface heat flux and 'ideal' burning rate data for PMMA.

Black PMMA regression data [23] is not included in Figure 8 for clear PMMA since it fell below the curve. This has been observed before, and attributed to differences in molecular structure or pigmentation effects [9]. The fact that ignition data agrees but burning rate data does not would seem to indicate that the radiant exchange in the presence of the visible high temperature flame may be different for the two materials, where black PMMA absorbs only at the surface, but the clear may be absorbing in-depth as well. The increased absorption in-depth could contribute to the observed higher burning rates.

Also in Fig. 8, a second equivalent gravity axis is again shown, using the same stretch scaling discussed above, along with normal cone regression rate-heat flux data [12]. This axis is only a scaling approximation to demonstrate that as gravity increases, regression rate increases since the flame is pressed closer to the fuel at higher $\mathrm{g}$ levels, increasing the burning rate. 


\section{CONCLUDING REMARKS}

ELSA ignition delay and burning rate data can be compared with data in other geometries and gravity levels using flow similarity. Correlations of combined radiative and convective heat transfer effects on the ignition delay (cooling effect) and burning rate (heating effect) are provided that collapse the data from disparate test environments. When convective heat transfer is accounted for in the net heat flux to the solid, normal gravity material flammability test methods for ignition delay or burning rate can be applied to low gravity environments.

\section{ACKNOWLEDGMENTS}

The author would like to acknowledge the contributions of college interns Christina Inman, and Elizabeth Paoletti.

\section{REFERENCES}

[1] Foutch, D.W., and T'ien, J.S., "Extinction of a Stagnation-Point Diffusion Flame at Reduced Gravity", AIAA J. 25 (7), 1987, p. 972-976, http://dx.doi.org/10.2514/3.9730

[2] Olson, S.L., and T'ien, J.S., "Buoyant Low Stretch Diffusion Flames Beneath Cylindrical PMMA Samples", Combust. Flame 121, 2000, p. 439-452, http://dx.doi.org/10.1016/S00102180(99)00161-3

[3] Armstrong, J.B., Olson, S.L., and T'ien, J.S., "Transient Model and Experimental Validation of Low Stretch Solid-Fuel Flame Extinction and Stabilization in Response to a Step Change in Gravity", Combust. Flame 147, 2006, p. 262-277, http://dx.doi.org/10.1016/j.combustflame.2006.09.007

[4] Olson, S.L., Beeson, H.D., Haas, and J.P., Baas, J.S., "An Earth-Based Equivalent Low Stretch Apparatus for Material Flammability Assessment in Microgravity and Extraterrestrial Environments", Proc. Combust. Inst. 30(2), 2005, p. 2335-2343, http://dx.doi.org/10.1016/j.proci.2004.08.044

[5] Miller, F.J., Olson, S.L., Gokoglu, and S.A., Ferkul, P.V., "Material Flammability Test Methods for Achieving Simulated Low-Gravity Conditions", $5^{\text {th }}$ US Combustion Meeting, The Combustion Institute, San Diego, CA, March 25-28, 2007.

[6] McGrattan, K., Klein, B., Hostikka, and S., Floyd, J., "Fire Dynamics Simulator User's Guide", NIST Special Publication 1019-5, Gaithersburg, MD, 2007, p. 1-206. Also http://fire.nist.gov/fds/.

[7] Wichman, I.S., "Flame Spread in an Opposed Flow with a Linear Velocity Gradient", Combust. Flame 50, 1983, p. 287-304, http://dx.doi.org/10.1016/0010-2180(83)90071-8

[8] Roslon, M., Olenick, S., Zhou, Y.Y., Walther, D.C., Torero, J.L., Fernandez-Pello, A.C., and Ross, H.D., "Microgravity Ignition Delay of Solid Fuels in Low Velocity Flows", AIAA J. 39 (12), 2001, p. 2336-2342, http://dx.doi.org/10.2514/2.1239

[9] Rhodes, B.T., and Quintiere, J.G., "Burning Rate and Flame Heat Flux for PMMA in a Cone Calorimeter", Fire Safety Journal 26, 1996, p. 221-240, http://dx.doi.org/10.1016/S0379$\underline{7112(96) 00025-2}$

[10] Ivanov, A.V., Balashov, Ye.V., Andreeva, T.V., and Melikhov, A.S., "Experimental Verification of Material Flammability in Space", NASA CR-1999-209405, NASA Glenn Research Center, Cleveland, OH, 1999, p. 1-61.

[11] Ivanov, A.V., Alymov, V.F., Smirnov, A.B., Shalayev, S.P., Belov, D.Ye., Balashov, Ye. V., Andreeva, T.V., Semenov, A.V., Melikhov, A.S., Bolodyan, I.A., and Potyakin, V. I., "Preliminary Results of the Third Test Series of Nonmetal Material Flammability Evaluation in SKOROST Apparatus on the Space Station Mir, NASA CP-1999-208917, NASA Glenn Research Center, Cleveland, OH, 1999, p. 47-50. 
[12] Tewarson, A., and Pion, R.F., "Flammability of Plastics - I. Burning Intensity", Combust. Flame 26, 1976, p. 85-103, http://dx.doi.org/10.1016/0010-2180(76)90059-6

[13] T'ien, J.S., Singhal, S.N., Harrold, and D.P., Prahl, J.M., "Combustion and Extinction in the Stagnation-Point Boundary Layer of a Condensed Fuel", Combust. Flame 33, 1978, p. 55-68, http://dx.doi.org/10.1016/0010-2180(78)90045-7

[14] Ohtani, H., Akita, K., and Hirano, T., "An analysis of bottom stagnation region combustion of polymeric material pieces under natural convection", Combust. Flame 53, 1983, p. 33-40, http://dx.doi.org/10.0.3.248/0010-2180(83)90004-4

[15] Olson, S.L., Kashiwagi, T., Fujita, O., Kikuchi, M., and Ito, K., "Experimental Observations of Spot Radiative Ignition and Subsequent Three-Dimensional Flame Spread over Thin Cellulose Fuels", Combust. Flame 125, 2001, p. 852-864, http://dx.doi.org/10.1016/S0010-2180(00)00249-2

[16] Tewarson, A., "Generation of heat and chemical compounds in fires", The SFPE Handbook of Fire Protection Engineering (3rd Edition). Section 3, Chapter 4. The National Fire protection Association Press: Quincy, MA, 2002, p. 3-161.

[17] Dietenberger, M.A., "Ignitability Analysis Using the Cone Calorimeter and Lift Apparatus", Proc. Intl. Conf. Fire Safety, Columbus, OH, Volume, 22, Product Safety Corp., 1996, p. 189-197.

[18] Quintiere, J.G., "A theoretical basis for flammability properties", Fire and Materials 30, 2005, p. 175-214, http://dx.doi.org/10.1002/fam.905.

[19] Mowrer, F.W., "An Analysis of Effective Thermal Properties of Thermally Thick Materials", NIST GCR 03-855, Gaithersburg, MD, 2003, p. 1-27.

[20] Mulville, D., "Flammability, odor, offgassing, and compatibility requirements and test procedures for materials in environments that support combustion", NASA-STD-6001, NASA Marshall Space Flight Center, Huntsville, AL, 1998, p. 1-70.

[21] Fernandez-Pello, A.C., "The Solid Phase", Chapter 2, Combustion Fundamentals of Fire, Academic Press, Cox, G. (Ed.), 1995, ISBN-13 978-0-470-09113-5 (HB).

[22] Meola, C., "A New Correlation of Nusselt Number for Impinging Jets", Heat Transfer Engineering 30(3), 2009, p. 221-228, http://dx.doi.org/10.1080/01457630802304311.

[23] Quintiere, J.G., and Rhodes, B.; "Fire Growth Models for Materials", NIST-GCR-94-647, Gaithersburg, MD, 1994, p. 1-49. 